OPEN ACCESS

Edited by:

Hsien-Yeh Chen,

National Taiwan University, Taiwan

Reviewed by:

Guoqing Pan,

Jiangsu University, China

Gloria Huerta-Angeles,

Contipro Inc., Czechia

*Correspondence:

Tzong-Rong Ger sunbow@cycu.org.tw

Specialty section:

This article was submitted to

Polymer Chemistry,

a section of the journal

Frontiers in Chemistry

Received: 31 October 2018 Accepted: 04 February 2019 Published: 25 February 2019

Citation:

Wang W-J, Huang Y-C, Su C-M and Ger T-R (2019) Multi-Functional Drug

Carrier Micelles With

Anti-inflammatory Drug.

Front. Chem. 7:93

doi: 10.3389/fchem.2019.00093

\section{Multi-Functional Drug Carrier Micelles With Anti-inflammatory Drug}

\author{
Wei-Jie Wang ${ }^{1,2}$, Yin-Chou Huang ${ }^{2}$, Chao-Ming Su ${ }^{2}$ and Tzong-Rong Ger ${ }^{2 *}$ \\ ${ }^{1}$ Division of Nephrology, Department of Internal Medicine, Taoyuan General Hospital, Ministry of Health and Welfare, \\ Taoyuan, Taiwan, ${ }^{2}$ Department of Biomedical Engineering, Chung Yuan Christian University, Taoyuan, Taiwan
}

The multi-functional micelles poly( $N$-isopropylacrylamide-co- $N, N$-dimethylacrylamideco-10 undecanoic acid)/CM-Dextran $\mathrm{Fe}_{3} \mathrm{O}_{4}$ (PNDU/CM-Dex $\mathrm{Fe}_{3} \mathrm{O}_{4}$ ) were poly (NIPAAm-Co-DMAAm-Co-UA) (PNDU) grafting hydrophilic CM-Dextran $\mathrm{Fe}_{3} \mathrm{O}_{4}$ which possess $\mathrm{pH}$-dependent temperature response and magnetic response. In this research, anti-inflammation drug Hesperetin was encapsulated by micelles using membrane dialysis method to obtain the different ratio of Hesperetin-embedded $\mathrm{P}_{5} \mathrm{DF}_{10}, \mathrm{P}_{10} \mathrm{DF}_{10}$, and $\mathrm{P}_{20} \mathrm{DF}_{10}$. These micelles were characterized by Fourier transform infrared spectroscopy, ${ }^{1} \mathrm{H}-\mathrm{NMR}$, thermogravimetric analyzer, and superconducting quantum interference device magnetometer. The morphology and particle size of micelles was observed by transmission electron microscopy and dynamic light scattering. The low critical solution temperature of the $\mathrm{P}_{10} \mathrm{DF}_{10}$ micelles is in $\mathrm{pH} 6.6$ at about $37.76^{\circ} \mathrm{C}$ and in $\mathrm{pH} 7.4$ at about $41.70^{\circ} \mathrm{C}$. The biocompatibility of micelles was confirmed by cytotoxicity study. Inflammatory inhibition of hesperetin-embedded $\mathrm{P}_{10} \mathrm{DF}_{10}$ micelles also studied through RAW264.7. Hesperetin-embed $P_{10} D_{10}$ micelles suppressed LPS-induced inflammatory response. Via immunofluorescence cell staining demonstrate that Hesperetin-embed $\mathrm{P}_{10} \mathrm{DF}_{10}$ micelles inhibited the activation of NF-kB p60 and markedly attenuated in a drug dose-dependent manner. At a concentration of 1,000 $\mathrm{ug} / \mathrm{ml}$, an inflammatory rate can be reduced to $36.9 \%$. Based on these results, the hesperetin-embed $\mathrm{P}_{10} \mathrm{DF}_{10}$ micelles had successfully synthesized and enable to carry and release the anti-inflammatory drugs, which instrumental for biomedical therapy and applications.

Keywords: drug carrier, temperature response micelles, pH response micelles, magnetic micelles, antiinflammatory drug

\section{INTRODUCTION}

Inflammation is the common response to injured vascular living tissue. Chemical and physical agents, microbial infections, inappropriate immunological responses or other issues may cause inflammation. The purpose of inflammation is to eliminate the microorganisms, enclose the injury, inactivate toxin so that the tissue or organ can be repaired (Cline M. J., 1970; Morson, 1970). However, some inflammation processes can be an insidious effect on the noxious sensitive reaction in progressive organ damage with the inflammatory mediators especially occur in chronic inflammation (Shin et al., 2008). For example, it is widely accepted that inflammation plays an important role in atherosclerotic plaque formation (Ross, 1999). Some approaches provided to overcome inflammation issue. Pan et al. (2015) presented a useful strategy for the release of anti-inflammatory drug by simply loading enzyme-sensitive polymeric prodrug in the scaffold 
materials to achieve full-course inhibition of biodegradationinduced inflammatory response. Current approaches mainly focus on the biomodification of the polymeric components for loading of anti-inflammatory drugs (Yoon et al., 2008; Kum et al., 2014; Yuan et al., 2014). Mostly, in order to increase the metabolic activity, inflammation foci will occur in an increase in temperature and an acidic environment (Naghavi et al., 2002). Since inflammation foci could be lead in the integration of some conditions in the living body, it is important in the design of smart responsive anti-inflammatory drug carrier of micelles. It can effectively prevent the disorder of drug delivery as inflammation is being suffered. The smart amphiphilic copolymers are proposed and characterized by their different functionally stimuli-responsive behavior, which is essentially dictated from the functional groups presented by the polymer chain. The most commonly utilized stimuli are temperature, $\mathrm{pH}$, magnetic, light, and ionic interactions. The temperature responsive poly(N-isopropylacrylamide) (PNIPAAm) has lower critical solution temperature (LCST), above LCST the polymer is well dispersed in an aqueous solution or substrate surface, and below LCST the polymer structure deforms for releasing the enclosed drug or surface attached molecules. Guoqing Pan et al. employed an imprinting methodology for PNIPAAm-based molecular of thermo-responsive hydrogel with LCST control for harvesting cell sheets (Pan et al., 2013). PNIPAAm or its copolymers have attracted special attention because of their stable thermal response and employed to solubilize hydrophobic drugs to treatment sites (Soppimath et al., 2005; Schattling et al., 2014). Jia-Shen Wei et al. synthesized poly( $\mathrm{N}$-isopropylacrylamideco-acrylic acid-co-cholesteryl acrylate) encapsulated anticancer drug for intracellular delivery (Wei et al., 2005). Xiqun Jiang et al. prepared the temperature and $\mathrm{pH}$ response micelles of poly (NIPAAm-co-acrylic acid)- $b$-poly(caprolactone) to deliver an anti-cancer drug (Zhang et al., 2007). Doo Sung Lee et al. used $\mathrm{pH}$-responsive polymeric micelle based on PEG-poly ( $\beta$-amino ester)/(amido amine) to detect the cerebral ischemic area (Gao et al., 2011). Subhra Mohapatra et al. and Vronique Prat et al. combined micelles and magnetic particles to deliver a reporter DNA to rat brains (Das et al., 2014) and to derive tumor imaging and therapy (Schleich et al., 2014). Therefore, designing the micelles having a pH-dependent LCST slightly higher than the normal body temperature, drug delivery can be controlled in inflammation foci.

In this study, the multi-targeting drug carrier micelles were synthesized as shown in Figure 1. The main structure of the multi-targeting drug contained poly $N$-isopropylacrylamide (NIPAAm), N,N-dimethylacrylamide (DMAAm), and 10undecenoic acid (UA). The poly $N$-isopropylacrylamide (NIPAAm), N,N-dimethylacrylamide (DMAAm) were synthesized for temperature response, and the 10-undecenoic acids (UA) were synthesized for $\mathrm{pH}$-dependent LCST. The micelles of grafted modified magnetic nanoparticles, CMDextran $/ \mathrm{Fe}_{3} \mathrm{O}_{4}$, were used as they have magnetic manipulation characteristics for accumulating the micelles in the lesion area. The micelles embed with the anti-inflammatory drug Hesperetin which is a by-product in citrus fruits; as such, it can be easily absorbed by humans (Garg et al., 2001). It is verified to lower cholesterol (Bok et al., 1999; Shin et al., 1999; Kim et al., 2003) and to reduce inflammation (Lin et al., 2005). The treatment strategy for micelles is as which under the normal physiological $\mathrm{pH}$ value of 7.4, the LCST is above the normal body temperature of $37^{\circ} \mathrm{C}$, leading which to deformation and the release of the enclosed Hesperetin molecules. The lesion area can also be targeted by the external magnetic field through the grafted modified magnetic particle CM-Dextran $/ \mathrm{Fe}_{3} \mathrm{O}_{4}$ (CM$\mathrm{Dex} / \mathrm{Fe}_{3} \mathrm{O}_{4}$ ). Macrophage that has a vascular atherosclerotic inflammatory response was used in this study to verify the drug release test. RAW264.7 macrophages are considered to play essential roles in inflammation which was found to be uniquely effective for measuring inflammatory mediators. This cell line is a good model to study inflammatory responses, which can be activated by lipopolysaccharide (LPS) and trigger the production of inflammatory mediators (i.e., leukotrienes, NF- $\kappa \mathrm{B}$, TNF- $\alpha$, and ILs) (Rossol et al., 2011; Fan et al., 2013). Among these mediators, the expression of pro-inflammatory cytokine and adhesion molecules is regulated by nuclear factor- $\kappa \mathrm{B}$ (NF-кB), which is composed of p50 and p65 subunits (Francisco et al., 2013). To confirm the inflammatory responses in cell staining, we used immunofluorescence method to explore the

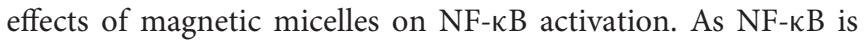
crucially implicated in inflammatory responses, the effects of magnetic micelles on NF- $\kappa$ B activation was explored in activated RAW264.7 macrophages induced by LPS in order to illuminate the anti-inflammatory effect of three magnetic micelles.

\section{MATERIALS AND METHODS \\ Preparation of Poly (NIPAAm-co-DMAAm- co-UA)/CM-Dex/Fe304 Micelles}

Firstly, UA was dissolved in an aqueous sodium hydroxide solution $(\mathrm{NaOH})$ and added NIPAAm and DMAAm in solution and stirred uniformly. Hydrochloric acid $(\mathrm{HCl})$ was used to titrate the solution to $\mathrm{pH}$ 6.7, and the initiator potassium peroxydisulfate and the chain transfer methyl-3mercaptopropionate agent were added to conduct a reaction for $4 \mathrm{~h}$. After dialysis and lyophilization, the $\mathrm{PNDU}-\mathrm{COOCH}_{3}$ was obtained. Since the functional group $\mathrm{COOCH}_{3}$ of synthesized PNDU-COOCH${ }_{3}$ was not easily grafted to magnetic particles, the functional group was modified with $\mathrm{NH}_{2}$ by hydrazine. The consecutive step was to modify poly (NIPAAm-co-DMAAmco-UA)- $\mathrm{COOCH}_{3}\left(\mathrm{PNDU}-\mathrm{COOCH}_{3}\right)$ to form poly (NIPAAmco-DMAAm-co-UA)-NHNH $\mathrm{NHNU}_{2}$ (PNHNH$\left.{ }_{2}\right)$. The PNDU$\mathrm{COOCH}_{3}$, hydrazine and methanol were uniformly stirred for $3 \mathrm{~h}$. After the reaction, dialysis and lyophilization were applied to obtain PNDU-NHNH$H_{2}$.

Dextran was a biocompatible, biodegradable and hydrophilic material (Draye et al., 1998), so we synthesize $\mathrm{Fe}_{3} \mathrm{O}_{4}$ with carboxymethyl dextran (CM-Dex). Carboxymethyl dextran magnetic particle $\left(\mathrm{CM}-\mathrm{Dex} / \mathrm{Fe}_{3} \mathrm{O}_{4}\right)$ was prepared by mixing ferric chloride $\left(\mathrm{FeCl}_{3} \cdot 6 \mathrm{H}_{2} \mathrm{O}\right)$, carboxymethyl dextran, hydrazine $\left(\mathrm{N}_{2} \mathrm{H}_{4}\right)$, and ferrous chloride $\left(\mathrm{FeCl}_{2} \cdot 4 \mathrm{H}_{2} \mathrm{O}\right)$, and finally obtained by dialysis and lyophilization. When prepared PNDU/CMDex- $\mathrm{Fe}_{3} \mathrm{O}_{4}$, the 3-(ethyliminomethyleneamino)-N,N-dimethylpropan-1-amine (EDC) and N-Hydroxysuccinimide used to 
pH \& temp. Responsive Micelles
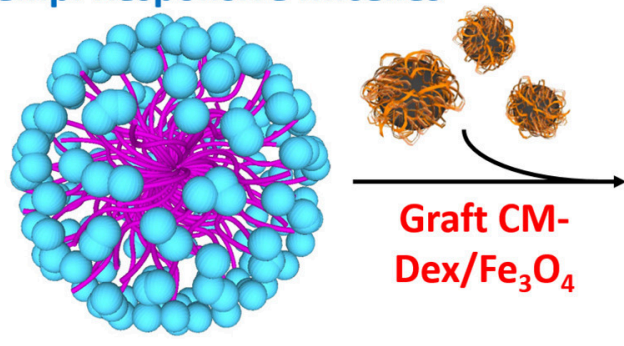

Magnetic/pH Responsive

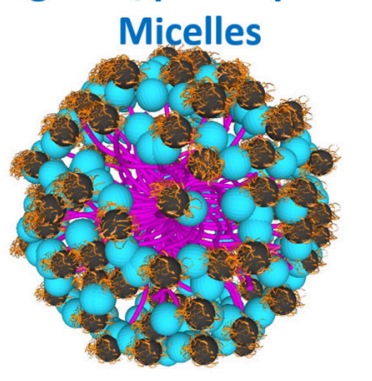

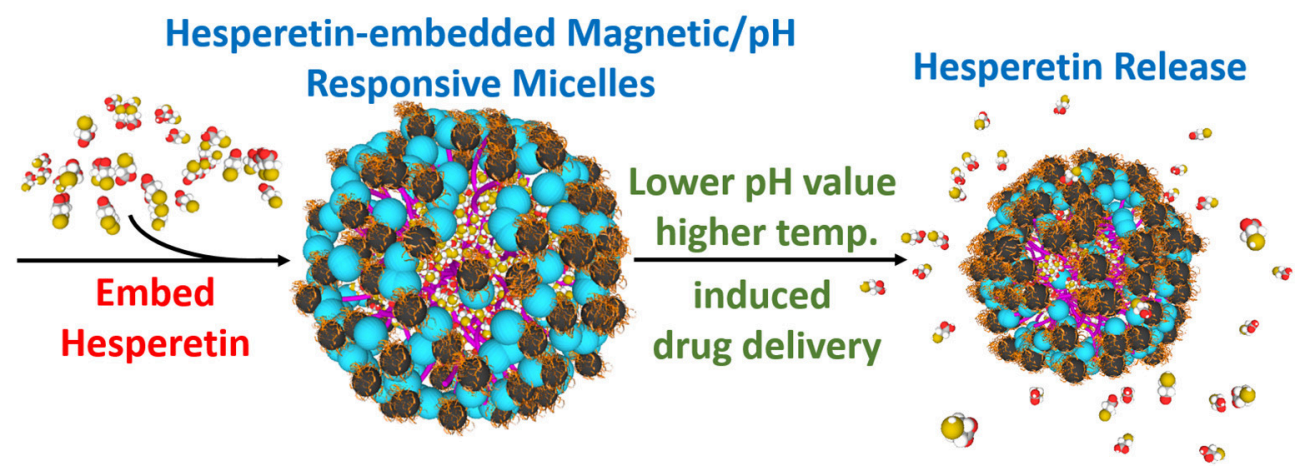

FIGURE 1 | Synthesis diagram of the multi-targeting drug delivery micelle with hesperetin embedded. The multi-targeting micelles are composed of NIPAAm, DMAAm, and UA. The micelles are grafted CM-Dextran/ $\mathrm{Fe}_{3} \mathrm{O}_{4}$ for magnetic manipulation. The inflammatory drug hesperetin are embedded into the micelles. Local inflammation area with relatively lower $\mathrm{pH}$ value and higher temperature led to the release of drug from the micelles. Target release to the inflammation area could be achieved by external magnetic field.

activate the carboxyl group of $\mathrm{CM}-\mathrm{Dex} / \mathrm{Fe}_{3} \mathrm{O}_{4}$, then adds different proportions of $\mathrm{PNDU}-\mathrm{NHNH}_{2}$ and uniformly stirs it. Further adjusting the molar concentration ratio of PNDU$\mathrm{NHNH}_{2}$ and $\mathrm{CM}-\mathrm{Dex} / \mathrm{Fe}_{3} \mathrm{O}_{4}$, the purpose of which was to regulate the temperature of the low critical solution temperature (LCST) of the temperature-responsive drug carrier micelles under different $\mathrm{pH}$ environments, thereby seeking to meet the temperature of the cardiovascular disease conditions. Then the Poly (NIPAAm-co-DMAAm-co-UA)/CM-Dex$\mathrm{Fe}_{3} \mathrm{O}_{4}$ (PNDU/CM-Dex- $\mathrm{Fe}_{3} \mathrm{O}_{4}$ ) obtained through dialysis and lyophilization. The chemical equation was showed in Figure 2.

\section{Drug (Hesperetin) Embed Procedure}

The drug (Hesperetin) embed procedure was to initially add $30 \mathrm{mg}$ of $\mathrm{PNDU} / \mathrm{CM}-\mathrm{Dex}-\mathrm{Fe}_{3} \mathrm{O}_{4}$ and $15 \mathrm{mg}$ of Hesperetin in $N, N$-dimethylmethanamide (DMF) solution for $2 \mathrm{~h}$, stirred evenly, and then put into $4^{\circ} \mathrm{C}$ environment for dialysis procedure to be drug-embedded. Collecting the retained solution after dialysis and lyophilization to obtain the micelles embedded Hesperetin.

\section{Characterization of PNDU/CM-Dex- $\mathrm{Fe}_{3} \mathrm{O}_{4}$ Micelles}

The multi-functional drug carrier micelle was characterized by Fourier transform infrared spectroscopy (FT-IR, IR-4200;
Jasco, Easton, MD, USA) which was mixed with potassium bromide $(\mathrm{KBr})$, ground into a powder, and made into the pellet. The pellet placed in the FT-IR instrument and scanned wavelength from 400 to $4,000 \mathrm{~cm}^{-1}$, the absorption wavelength of the functional group was analyzed. The graft ratio of the micelles would be the quantitative conversion of the integral area measured in Nuclear Magnetic Resonance Spectroscopy (NMR, Ascend 600, Bruker, USA) and the nuclear specie was ${ }^{1} \mathrm{H}$. The morphology of the PNDU/CM-Dex- $\mathrm{Fe}_{3} \mathrm{O}_{4}$ was examined by transmission electron microscope (FEG-TEM, Tecnai F30; Philips, USA). The particle size of the samples was measured by dynamic light scattering (DLS) (LS series, Beckman Coulter, USA).

The critical micelles concentration (CMC) and low critical solution temperature (LCST) were used to evaluate the functionality of micelles. To measure the CMC, the hydrophobic fluorescent agent 1,6-diphenyl-1,3,5-hexatriene (DPH) was embedded in the hydrophobic layer of the PNDU/CM-Dex$\mathrm{Fe}_{3} \mathrm{O}_{4}$ and measured the fluorescence intensity. The LCST of the multi-functional drug carrier micelles was derived by measuring the permeability of micelles dissolved in Phosphate Buffered Saline (PBS). In order to verify the magnetic properties of the micelles, the micelles were analyzed by the superconducting quantum interference device (SQUID, MPMS 5, Quantum Design, San Diego, CA, USA) and the thermogravimetric analysis (TGA). 

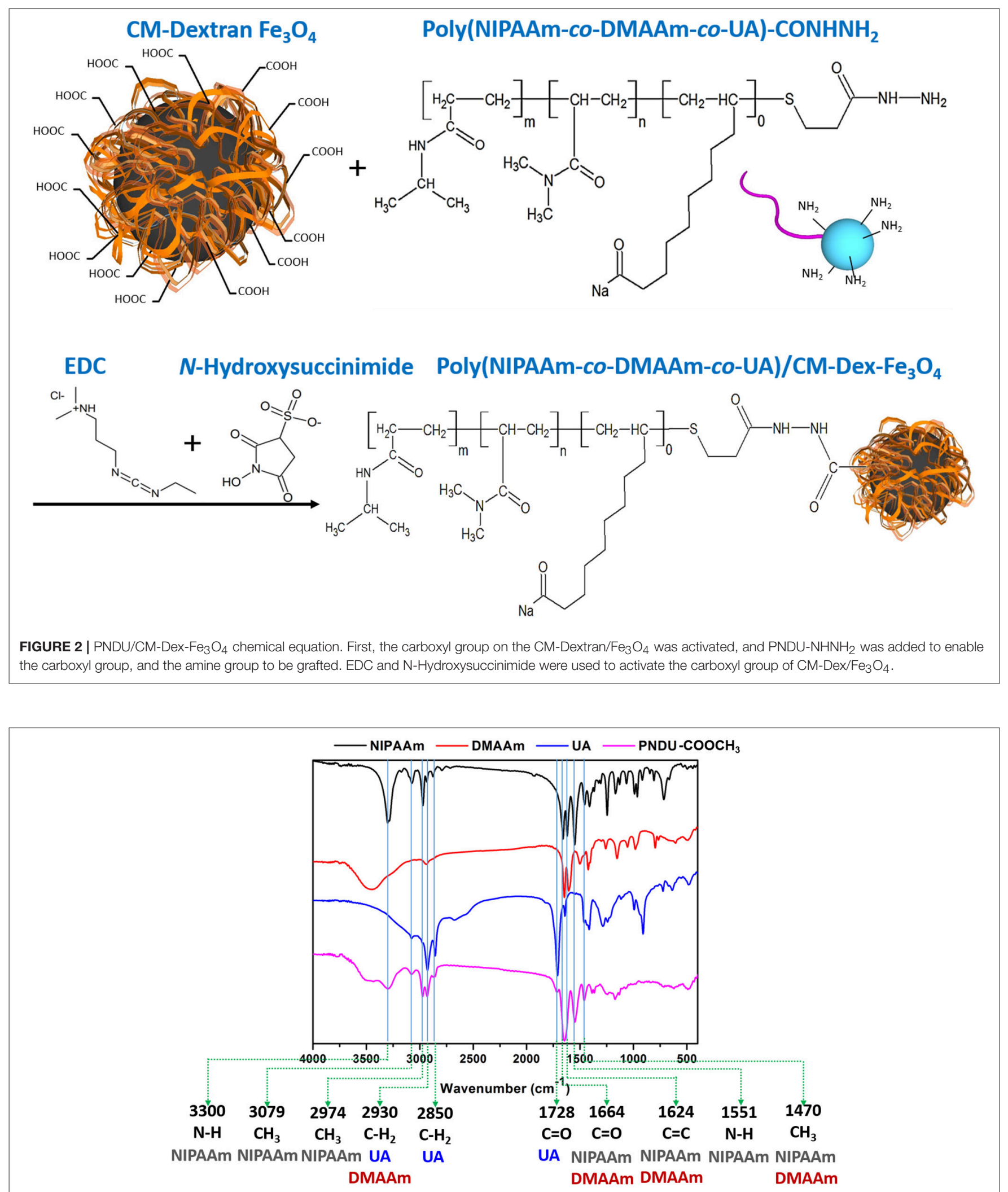

FIGURE 3 | Fourier transform infrared spectroscopy analysis of functional groups of NIPAAm, DMAAm, UA, and PNDU-COOCH${ }_{3}$. The characteristic peaks of NIPAAm, DMAAm, and UA can be seen in the spectrum of PNDU-COOCH 3 , which proved the successful synthesis. 


\section{Determination of Drug Loading Efficiency (LE\%) and Encapsulation Efficiency (EE\%) of Micelles}

Dimethylsulfoxide (DMSO) was used to disrupt the micellar structure to be then analyzed spectrophotometrically (ultraviolet-visible [UV-Vis] spectrophotometer; JASCO, Tokyo, Japan) at $231 \mathrm{~nm}$ for drug content. The equations we used for the estimation of $\mathrm{LE}$ and $\mathrm{EE} \%$ of Hesperetin in $\mathrm{P}_{5} \mathrm{DF}_{10}, \mathrm{P}_{10} \mathrm{DF}_{10}, \mathrm{P}_{20} \mathrm{DF}_{10}$ micelles were as follows (Zu et al., 2011; Mohamed et al., 2018):

$$
\begin{array}{r}
\mathrm{LE} \%=\frac{\text { Hesperetin weight in the micelles }}{\text { Weight of Hesperetin and polymer added }} \times 100 \% \\
\mathrm{EE} \%=\frac{\text { Hesperetin weight in the micelles }}{\text { Weight of Hesperetin added }} \times 100 \%
\end{array}
$$

\section{Drug (Hesperetin) Release Experiment}

The Hesperetin release experiment was to dissolve the lyophilized Hesperetin-embedded PNDU/CM-Dex- $-\mathrm{Fe}_{3} \mathrm{O}_{4}$ micelles in a PBS buffer solution of $\mathrm{pH} 6.6$ and $\mathrm{pH}$ 7.4, respectively, at a concentration of $1 \mathrm{mg} / \mathrm{ml}$. The two different $\mathrm{pH}$ solutions respectively heated to a fixed temperature which were the previously examined LCST. The extracted sample solution and the ethanol solution were configured as test solutions in ethanol/PBS ( $v: v=20: 80$ ), uniformly stirred, and detected by UV-Vis, and further compared to calculate the release amount of the Hesperetin in micelles.

\section{Micelles in vitro Test}

Micelles in vitro tests divided into cell viability testing and inflammation assessment. In cell viability testing, PNDU/CMDex- $\mathrm{Fe}_{3} \mathrm{O}_{4}$ micelles were co-cultured with L929 mouse fibroblasts and evaluated by MTT-assay. The experimental procedure was first to culture L929 mouse fibroblasts in 24 well-plate, the number of cells was $1 \times 10^{6} /$ well. The control group and the experimental group were divided and cultured for 1 day. The plate simultaneously illuminated with UV light to ensure sterility. Then inject culture medium containing PNDU/CM-Dex- $-\mathrm{Fe}_{3} \mathrm{O}_{4}$ into the plate of experimental group and co-culture with the cells. After co-culture, the survival co-cultured cells were judged by the absorbance of the control group. The scanning wavelength of $570 \mathrm{~nm}$ was set in the ELISA to measure the absorbance of MTT-assay, and the ratio of the experimental group to the control group was the cell viability.

This study used lipopolysaccharide (LPS) to induce the inflammatory response in RAW264.7 mouse macrophages/monocyte and co-culture with multi-functional drug carrier micelles for inflammatory evaluation. The amount of $5 \times 10^{4}$ cells $/ \mathrm{ml}$ of RAW264.7 mouse macrophage/monocyte was cultured in 96 well-plate, and the positive control group, the negative control group and the experimental group were distinguished. The positive control group contained only macrophage/monocyte and the culture medium; the negative control group was the macrophage/monocyte, the LPS, and the culture medium. The Hesperetin-embed PNDU/CM-Dex$\mathrm{Fe}_{3} \mathrm{O}_{4}$ micelles were added at 250,500 , and $1,000 \mu \mathrm{g} / \mathrm{ml}$ to the

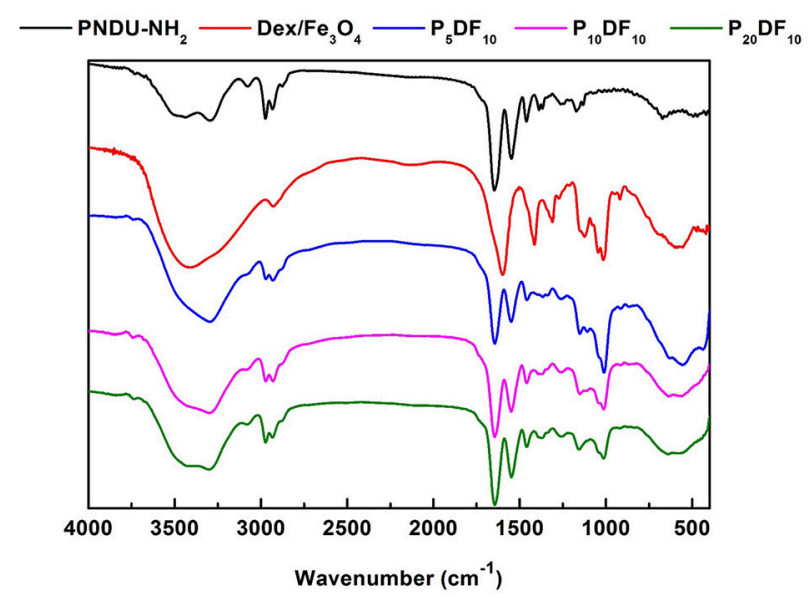

FIGURE 4 | Fourier transform infrared spectroscopy analysis of functional groups of PNDU- $\mathrm{NH}_{2}, \mathrm{CM}-\mathrm{Dex} / \mathrm{Fe}_{3} \mathrm{O}_{4}, \mathrm{P}_{5} \mathrm{DF}_{10}, \mathrm{P}_{10} \mathrm{DF}_{10}$, and $\mathrm{P}_{20} \mathrm{DF} \mathrm{F}_{10}$. The CM-Dex/ $/ \mathrm{Fe}_{3} \mathrm{O}_{4}$ were successfully grafted onto the $\mathrm{PNDU}-\mathrm{NH}_{2}$ by Fourier transform infrared spectroscopy

experimental group, respectively, and cultured for $24 \mathrm{~h}$. After the reaction was completed, the scanning wavelength of $540 \mathrm{~nm}$ was set in the ELISA to measure the absorbance.

\section{Immunofluorescence Staining on NF-kB p65}

To visualize the expression of NF- $\mathrm{KB}$ in cultured RAW264.7, cells were cultured in 24-well plates $\left(1 \times 10^{6}\right.$ cells per well $)$ and pretreated with PNDU/CM-Dex-Fe3O4 micelles $\mathrm{P}_{10} \mathrm{DF}_{10}$ $(250,500$, and $1,000 \mu \mathrm{g} / \mathrm{ml})$ for $1 \mathrm{~h}$ at $38^{\circ} \mathrm{C}$ and stimulated with LPS for $30 \mathrm{~min}$. The cells were then washed and fixed with a $4 \%$ paraformaldehyde for $30 \mathrm{~min}$ at $37^{\circ} \mathrm{C}$, permeabilized with $0.3 \%$ Triton X-100 for $15 \mathrm{~min}$, blocked with PBS containing $5 \%$ bovine serum albumin (BSA) for $30 \mathrm{~min}$. Next, the cells were processed for immunofluorescent staining with primary NF- $\kappa$ B p 65 antibody for $1 \mathrm{~h}$, and followed by incubation with a fluorescein (FITC)-labeled secondary antibody for $1 \mathrm{~h}$ before observation. Protein expressed of p65 in RAW264.7 exhibited green fluorescence and observed using a microscope. To create a phase-fluorescence mapping image, the phase contract, and green fluorescence images were overlaid, producing mapping fluorescence in areas of co-localization.

\section{RESULTS}

\section{Physical and Chemical Properties of Drug Carrier Micelles}

This study was based on the $\mathrm{pH}$ and temperature response polymer of poly(NIPAAm-co-DMAAm- $c o-\mathrm{UA})-\mathrm{COOCH}_{3}$ and it was modified to poly(NIPAAm-co-DMAAm-co-UA)$\mathrm{NHNH}_{2}$; subsequently. grafting CM-Dextran/ $/ \mathrm{Fe}_{3} \mathrm{O}_{4}$, led to the development of the multi-functional drug carrier micelles of poly(NIPAAM-co-DMAAm-co-UA)/CM-Dex- $\mathrm{Fe}_{3} \mathrm{O}_{4}$. 


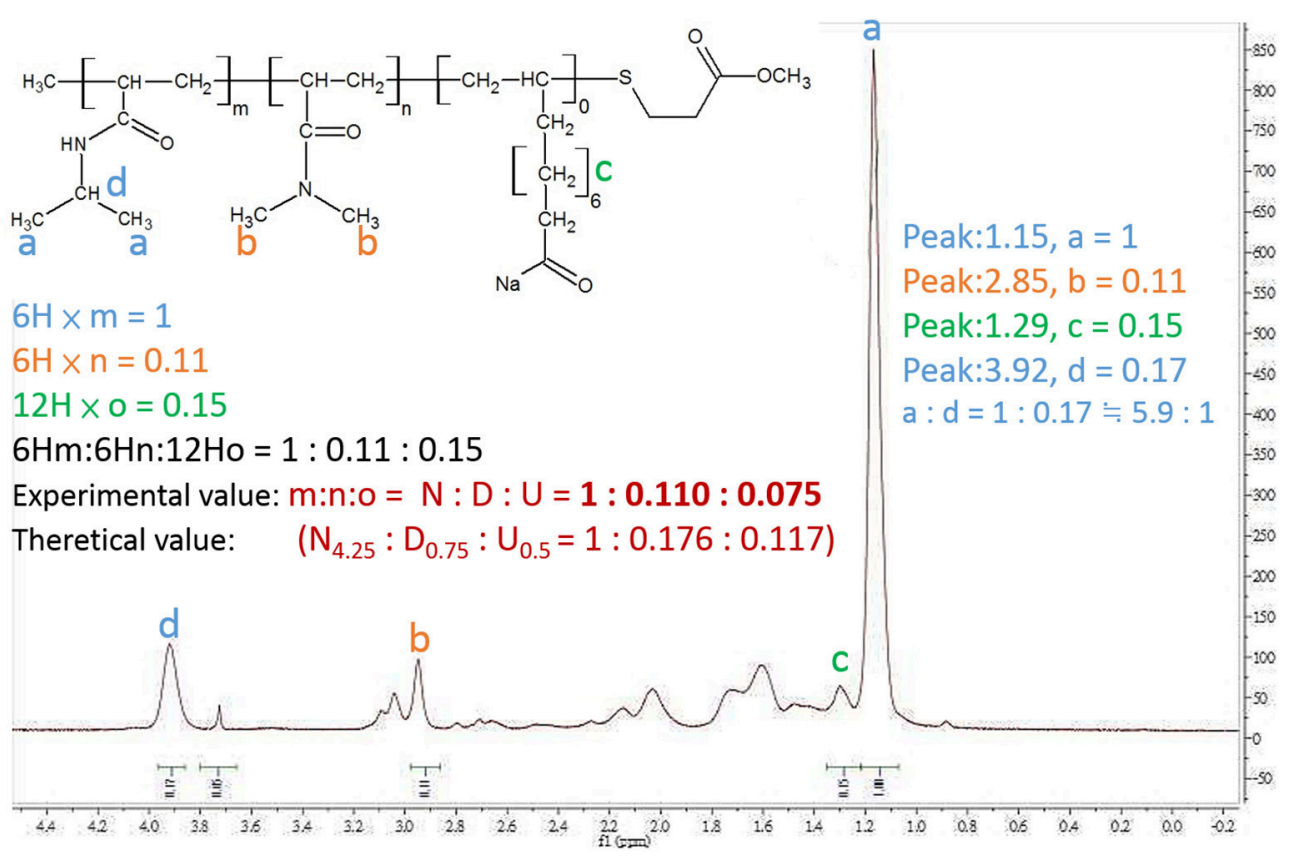

FIGURE $5 \mid{ }^{1} \mathrm{H}-\mathrm{NMR}$ spectrum showed the proton signal $\delta=1.15 \mathrm{ppm}$ of PNDU-COOCH${ }_{3} ; \delta=2.85$ ppm of NIPAAm, and $\delta=1.29$ of DMAAm which verified the PNDU-COOCH 3 composed of NIPAAm, DMAAm, and UA.

In this study, FT-IR was used to detect the vibrational absorption peak of the functional group of the material, thereby confirming that the synthesized micelles of PNDU$\mathrm{COOCH}_{3}$. PNDU-COOCH 3 micelles are synthesized from three monomers: NIPAAm, DMAAm, and UA. Figure 3 shows the FTIR spectra of NIPAAm, DMAAm, UA, and PNDU. The FT-IR of PNDU were found in the characteristic peaks of $\mathrm{NH}, \mathrm{CH}_{3}$ and $\mathrm{NH}$ of NIPAAm at 3,300, 3,079, 2,974, and 1,551 $\mathrm{cm}^{-1}$, respectively. Moreover, the 1,664, 1,728, 2,850, and 2,930 $\mathrm{cm}^{-1}$ were the $\mathrm{C}=\mathrm{O}$ and $\mathrm{CH}_{2}$ characteristic peaks of DMAAm and UA, respectively. It was also observed that DMAAm and UA were indeed grafted to PNDU-COOCH 3 . Since both NIPAAm and DMAAm have $\mathrm{C}=\mathrm{O}$ functional groups, a superposition occurs at $1,664 \mathrm{~cm}^{-1}$. At the same time, the $\mathrm{C}=\mathrm{C}$ functional group of NIPAAm at $1,624 \mathrm{~cm}^{-1}$ disappears' this proves that grafting occurs by broken $\mathrm{C}=\mathrm{C}$.

The PNDU/CM-Dex- $\mathrm{Fe}_{3} \mathrm{O}_{4}$ (PDF) functional group vibration absorption peak was also detected by FT-IR to confirm the synthesized micelles. The PDF micelles were synthesized by PNDU-NH $\mathrm{N}_{2}$ and CM-Dex $/ \mathrm{Fe}_{3} \mathrm{O}_{4}$, and the different ratios were adjusted: $\mathrm{PNDU}-\mathrm{NH}_{2}$ : CM-Dex/ $\mathrm{Fe}_{3} \mathrm{O}_{4}=5: 10\left(\mathrm{P}_{5} \mathrm{DF}_{10}\right)$, PNDU$\mathrm{NH}_{2}: \mathrm{CM}-\mathrm{Dex} / \mathrm{Fe}_{3} \mathrm{O}_{4}=10: 10\left(\mathrm{P}_{10} \mathrm{DF}_{10}\right)$, and PNDU-NH ${ }_{2}$ : $\mathrm{CM}-\mathrm{Dex} / \mathrm{Fe}_{3} \mathrm{O}_{4}=20: 10\left(\mathrm{P}_{20} \mathrm{DF}_{10}\right)$. The experimental results are shown in Figure 4; these include spectrum $\mathrm{PNDU}-\mathrm{NH}_{2}$, $\mathrm{Dex} / \mathrm{Fe}_{3} \mathrm{O}_{4}, \mathrm{P}_{5} \mathrm{DF}_{10}, \mathrm{P}_{10} \mathrm{DF}_{10}$, and $\mathrm{P}_{20} \mathrm{DF}_{10}$.

According to the FT-IR spectrum, 1,728, 1,664, and 1,551 $\mathrm{cm}^{-1}$ had the carbonyl group and nitrogen-hydrogen bond functional groups of PNDU-NH $\mathrm{NH}_{2}$, while 2,974, 2,930, and 1,470 $\mathrm{cm}^{-1}$ had the carbon-hydrogen bond functional group of PNDU-NH $\mathrm{N}_{2}$. This indicates that $\mathrm{P}_{5} \mathrm{DF}_{10}, \mathrm{P}_{10} \mathrm{DF}_{10}$, and $\mathrm{P}_{20} \mathrm{DF}_{10}$ each have the characteristics of PNDU- $\mathrm{NH}_{2}$. The characteristic peaks of the carbon-oxyl and iron-oxyl of CM-Dextran/ $/ \mathrm{Fe}_{3} \mathrm{O}_{4}$ at $1,111,1,011$, and $570 \mathrm{~cm}^{-1}$ meant that CM-Dextran/ $\mathrm{Fe}_{3} \mathrm{O}_{4}$ had indeed been grafted to PNDU. The higher the iron content of the micelles, the larger the signal. This further indicated that CM-Dextran/Fe3O4 was indeed grafted to the PNDU.

The nuclear magnetic resonance spectrometer $\left({ }^{1} \mathrm{H}-\mathrm{NMR}\right)$ was used to confirm the composite of PNDU-COOCH 3 . The ${ }^{1} \mathrm{H}$ NMR spectrum is shown in Figure 5, wherein "a" was the proton signal $\delta=1.15 \mathrm{ppm}$ of PNDU-COOCH 3 and " $\mathrm{b}$ " was the proton signal $\delta=2.85$ ppm of NIPAAm; " $\mathrm{c}$ " was the proton signal $\delta=1.29$ of DMAAm; this verified that the $\mathrm{PNDU}-\mathrm{COOCH}_{3}$ was polymerized of NIPAAm, DMAAm, and UA.

The morphology of PNDU-COOCH $3, \mathrm{P}_{5} \mathrm{DF}_{10}, \mathrm{P}_{10} \mathrm{DF}_{10}$, and $\mathrm{P}_{20} \mathrm{DF}_{10}$ was examined by TEM and DLS, as shown in Figure 6. The TEM image showed that the higher the iron content of the micelles, the higher the surface density of the iron in the image. The DLS results showed that the average particle size of PNDU$\mathrm{COOCH}_{3}$ was $223.68 \pm 40.19 \mathrm{~nm}$; for $\mathrm{P}_{5} \mathrm{DF}_{10}$ it was $422.07 \pm$ $49.55 \mathrm{~nm}$; for $\mathrm{P}_{10} \mathrm{DF}_{10}$ it was $401.33 \pm 17.31 \mathrm{~nm}$; and for $\mathrm{P}_{20} \mathrm{DF}_{10}$ it was $417.73 \pm 41.31 \mathrm{~nm}$.

\section{Functional Manifestation of Drug Carrier Micelles}

The functional manifestation of the micelles includes the CMC, the LCST and the change in the particle size of the micelles under temperature changes in order to realize the feasibility of the micelles for drug release. Table 1 shows that the LCST of $\mathrm{PNDU}_{-\mathrm{COOCH}}$ was $\mathrm{pH}$ 6.6: $32.40 \pm 1.00^{\circ} \mathrm{C}$ and $\mathrm{pH}$ 7.4: 36.50 $\pm 0.50^{\circ} \mathrm{C}$. This indicated that adding more DMAAm to NIPAAm 


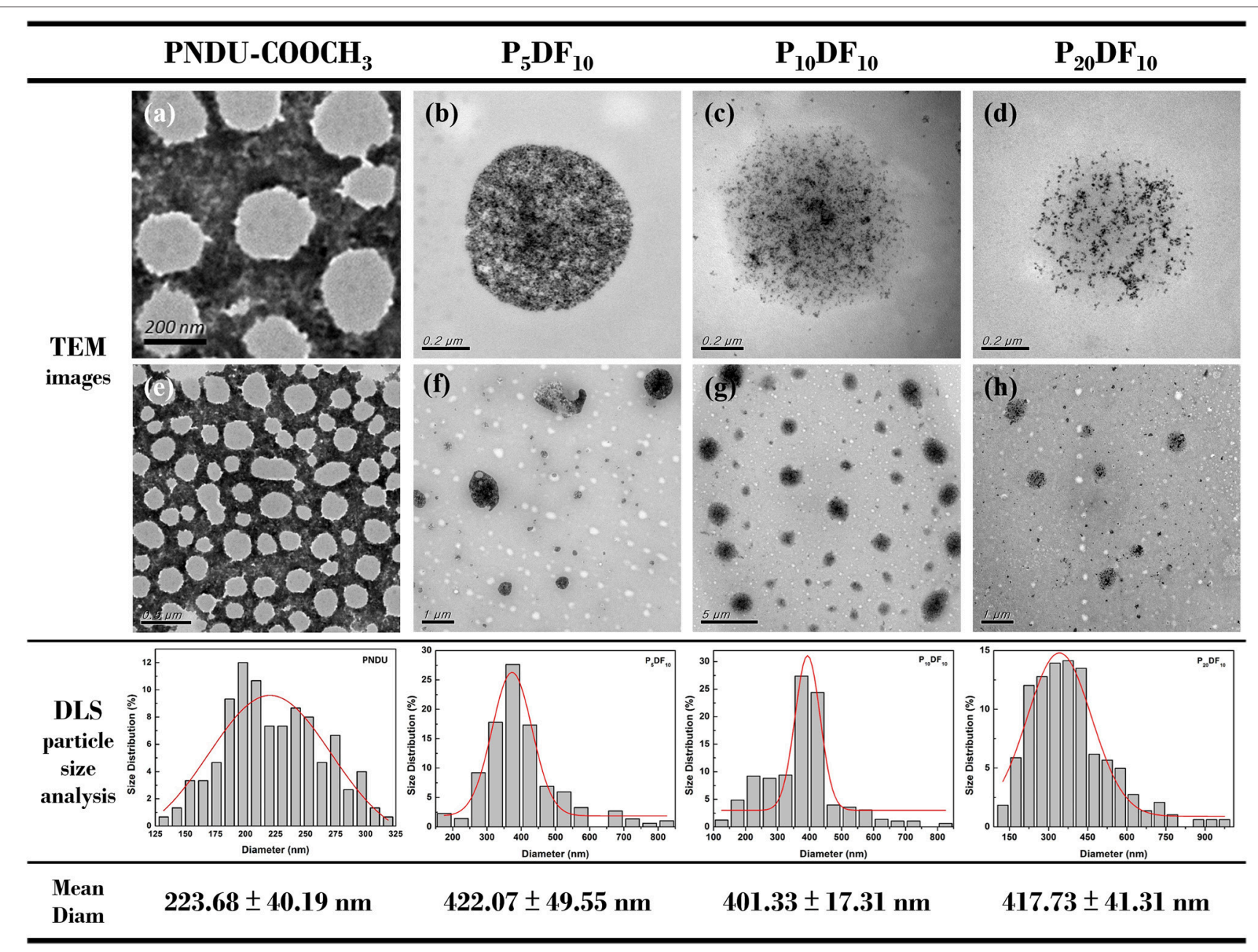

FIGURE 6 | TEM image of $(\mathbf{a}, \mathbf{e})$ PNDU-COOCH 3 , (b,f) $\left.P_{5} D F_{10}, \mathbf{( c , g}\right) P_{10} D F_{10}$, and $(\mathbf{d}, \mathbf{h}) P_{20} D F_{10}$. The particles size of $P N D U, P_{5} D F_{10}, P_{10} D F_{10}$, and $P_{20} D F_{10}$ were 223.68, 422.07, 401.33, and $417.73 \mathrm{~nm}$.

TABLE 1 | The LCST of the PNDU-COOCH $3, \mathrm{P}_{5} \mathrm{DF}_{10}, \mathrm{P}_{10} \mathrm{DF}_{10}$, and $\mathrm{P}_{20} \mathrm{DF}_{10}$.

\begin{tabular}{lccc}
\hline Sample & Environmental pH value & LCST $\left({ }^{\circ} \mathbf{C}\right)$ & $\mathbf{\Delta T}\left({ }^{\circ} \mathbf{C}\right)$ \\
\hline PNDU-COOCH & & & \\
& 6.6 & $32.40 \pm 1.00$ & 4.10 \\
$\mathrm{P}_{5} \mathrm{DF}_{10}$ & 7.4 & $36.50 \pm 0.50$ & \\
& 6.6 & $37.50 \pm 1.00$ & 2.83 \\
$\mathrm{P}_{10} \mathrm{DF}_{10}$ & 7.4 & $40.33 \pm 1.08$ & \\
& 6.6 & $37.76 \pm 0.59$ & 3.94 \\
$\mathrm{P}_{20} \mathrm{DF}_{10}$ & 7.4 & $41.70 \pm 1.14$ & \\
& 6.6 & $35.86 \pm 0.51$ & 3.14 \\
\end{tabular}

helped to enhance the effect of the modulating LCST. It was found that the $\mathrm{P}_{10} \mathrm{DF}_{10}$ micelles showed the highest $\mathrm{EE} \%$ (42.23 \pm 2.11 ) among other samples (as shown in Table 2) and exhibited the $\mathrm{LE} \%$ of $3.44 \pm 0.18 . \mathrm{P}_{5} \mathrm{DF}_{10}$ micelles showed the $\mathrm{EE} \%$ was $12.55 \pm 3.77$ and $\mathrm{LE} \%$ was $2.83 \pm 0.21 ; \mathrm{P}_{20} \mathrm{DF}_{10}$ micelles showed the $\mathrm{EE} \%$ was $35.45 \pm 5.33$ and $\mathrm{LE} \%$ was $3.51 \pm 0.33$. Grafting
TABLE 2 | Drug loading and encapsulation efficiencies at different ratio of PNDU $-\mathrm{Fe}_{3} \mathrm{O}_{4}$ micelles.

\begin{tabular}{lcc}
\hline Sample & LE\% & EE\% \\
\hline $\mathrm{P}_{5} \mathrm{DF}_{10}$ & $2.83 \pm 0.21$ & $12.55 \pm 3.77$ \\
$\mathrm{P}_{10} \mathrm{DF}_{10}$ & $3.44 \pm 0.18$ & $42.23 \pm 2.11$ \\
$\mathrm{P}_{20} \mathrm{DF}_{10}$ & $3.51 \pm 0.33$ & $35.45 \pm 5.33$
\end{tabular}

UA allows the amphiphilic polymer to regulate different LCST temperatures due to changes in the $\mathrm{pH}$ environment. The LCST of the $\mathrm{P}_{5} \mathrm{DF}_{10}, \mathrm{P}_{10} \mathrm{DF}_{10}$, and $\mathrm{P}_{20} \mathrm{DF}_{10}$ LCST were $\mathrm{P}_{5} \mathrm{DF}_{10}$ at $\mathrm{pH}$ 6.6: $37.50 \pm 1.00^{\circ} \mathrm{C}, \mathrm{pH} 7.4: 40.33 \pm 1.08^{\circ} \mathrm{C} \mathrm{P}_{10} \mathrm{DF}_{10}$ at $\mathrm{pH}$ 6.6: $37.76 \pm 0.59^{\circ} \mathrm{C}$, pH 7.4: $41.70 \pm 1.14^{\circ} \mathrm{C} ; \mathrm{P}_{20} \mathrm{DF}_{10}$ at $\mathrm{pH}$ 6.6: 35.86 $\pm 0.51^{\circ} \mathrm{C}, \mathrm{pH} 7.4: 39.00 \pm 0.52^{\circ} \mathrm{C}$. Due to the hydrophilicity of the CM-Dextran $/ \mathrm{Fe}_{3} \mathrm{O}_{4}$ on the surface of PNDU- $\mathrm{NH}_{2}$, the hydrogen bond on the surface of the micelles became tighter. This made the hydrogen bond less prone to break, it enhanced its hydrophilic properties, and it increased its interaction with water. 


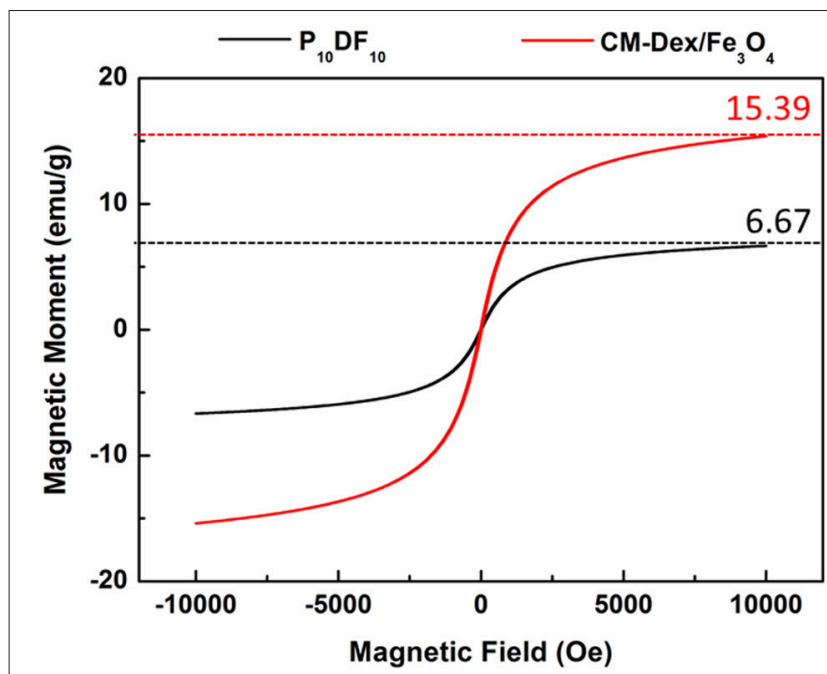

FIGURE 7 | SQUID verification of CM-Dex/ $\mathrm{Fe}_{3} \mathrm{O}_{4}$ and $\mathrm{P}_{10} \mathrm{DF} \mathrm{F}_{10}$. The saturation magnetic moment of $\mathrm{CM}-\mathrm{Dex} / \mathrm{Fe}_{3} \mathrm{O}_{4}$ and $\mathrm{P}_{10} \mathrm{DF}_{10}$ were 15.39 $\mathrm{emu} / \mathrm{g}$ and $6.67 \mathrm{emg} / \mathrm{g}$ which represented the $\mathrm{P}_{10} \mathrm{DF}_{10}$ contained $43.33 \%$ $\mathrm{CM}-\mathrm{Dex} / \mathrm{Fe}_{3} \mathrm{O}_{4}$

The LCST of $\mathrm{P}_{5} \mathrm{DF}_{10}, \mathrm{P}_{10} \mathrm{DF}_{10}$, and $\mathrm{P}_{20} \mathrm{DF}_{10}$ appeared in higher response temperatures than did $\mathrm{PNDU}-\mathrm{COOCH}_{3}$.

\section{PDF Micelles Magnetic Verification and Magnetic Content Analysis}

This study verified that PDF micelles have magnetic properties for magnetic targeting. The saturation magnetization results detected by SQUID are shown in Figure 7. The magnetic moment of $\mathrm{CM}-\mathrm{Dex} / \mathrm{Fe}_{3} \mathrm{O}_{4}$ is $15.39 \mathrm{emu} / \mathrm{g}$, while the magnetic moment of the $\mathrm{P}_{10} \mathrm{DF}_{10}$ micelles is $6.67 \mathrm{emu} / \mathrm{g}$; this verified that magnetic property was contained. The content of CMDex $/ \mathrm{Fe}_{3} \mathrm{O}_{4}$ in $\mathrm{P}_{10} \mathrm{DF}_{10}$ could be estimated by the ratio of the saturation magnetic moment of the CM-Dex/ $\mathrm{Fe}_{3} \mathrm{O}_{4}$ and $\mathrm{P}_{10} \mathrm{DF}_{10}$ micelles. The ratio between $\mathrm{CM}-\mathrm{Dex} / \mathrm{Fe}_{3} \mathrm{O}_{4}$ and $\mathrm{P}_{10} \mathrm{DF}_{10}$ was $43.33 \%$, which indicated that the $\mathrm{P}_{10} \mathrm{DF}_{10}$ contained $43.33 \% \quad \mathrm{CM}-\mathrm{Dex} / \mathrm{Fe}_{3} \mathrm{O}_{4}$. This result was greatly consistent with the proportion of $\mathrm{P}_{10} \mathrm{DF}_{10}$ (PNDU-NH2: CM$\left.\mathrm{Dex} / \mathrm{Fe}_{3} \mathrm{O}_{4}=10: 10\right)$.

Thermo-gravimetric analysis was used to predict the structure and composition of the material. In this study, TGA was used to investigate the synthesis ratio of grafted CM-Dex $/ \mathrm{Fe}_{3} \mathrm{O}_{4}$. The TGA results, shown in Figure 8, reflect that the residual amount of CM-Dextran $/ \mathrm{Fe}_{3} \mathrm{O}_{4}, \mathrm{P}_{10} \mathrm{DF}_{10}$, and $\mathrm{PNDU}-\mathrm{NH}_{2}$ was 37.76, 21.34, and 7.86\%. The $\mathrm{P}_{10} \mathrm{DF}_{10}$ was composed of PNDU$\mathrm{NH}_{2}$ and $\mathrm{CM}-$ Dextran $/ \mathrm{Fe}_{3} \mathrm{O}_{4}$, and that each proportion of the composition could be extrapolated from the residual amount. The results of the content of CM-Dextran/ $\mathrm{Fe}_{3} \mathrm{O}_{4}$ in $\mathrm{P}_{10} \mathrm{DF}_{10}$ were $45.08 \%$, which was similar to those found in the SQUID analysis.

\section{Drug (Hesperetin) Release Experiment}

The drug carrier Hesperetin-embed $\mathrm{P}_{10} \mathrm{DF}_{10}$ micelles controlled the release rate of the drug at different $\mathrm{pH}$ values through its LCST characteristics. The purpose was to release the drug

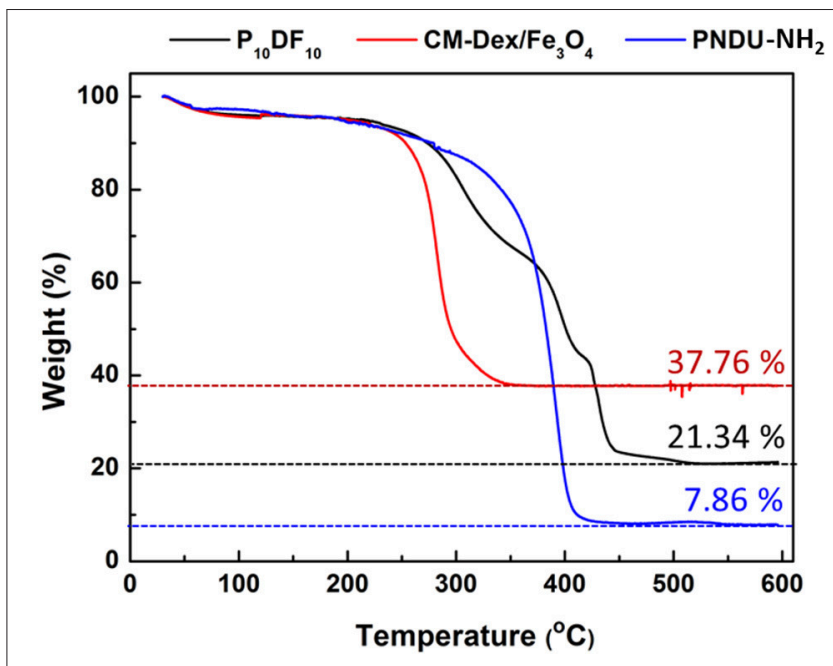

FIGURE 8 | $\mathrm{P}_{10} \mathrm{DF}_{10}$ TGA analysis. The residual amount of CM-Dextran/ $/ \mathrm{Fe}_{3} \mathrm{O}_{4}, \mathrm{P}_{10} \mathrm{DF}_{10}$, and PNDU-NH $\mathrm{H}_{2}$ was $37.76,21.34$, and $7.86 \%$ that extrapolated the content of $\mathrm{CM}$-Dextran/ $/ \mathrm{Fe}_{3} \mathrm{O}_{4}$ in $\mathrm{P}_{10} \mathrm{DF}_{10}$ was $45.08 \%$.

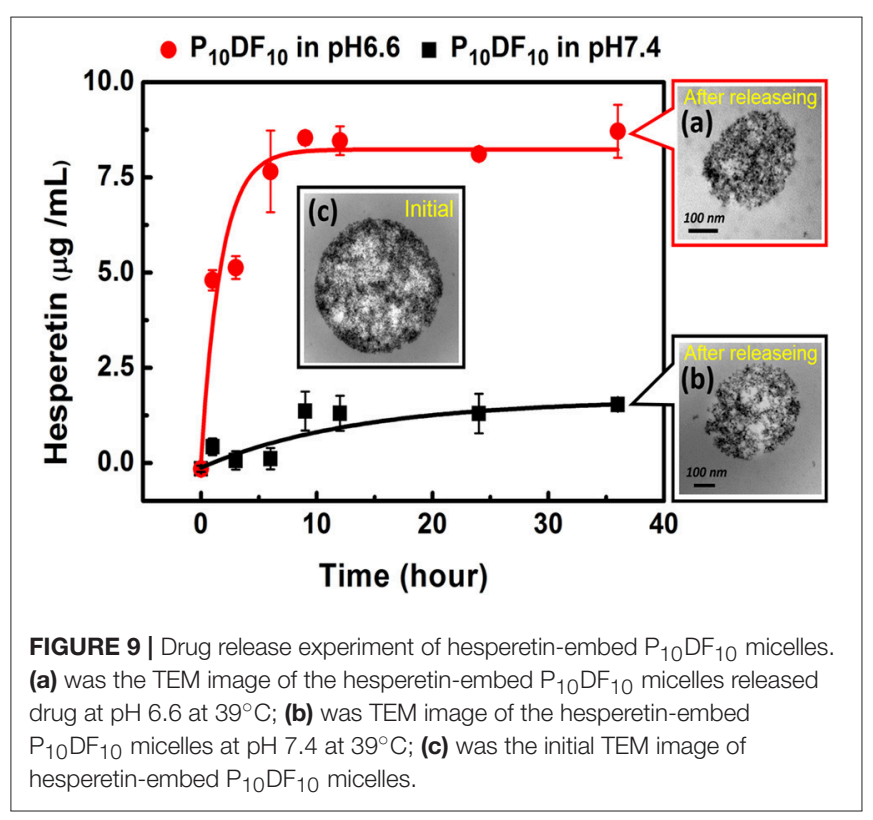

(Hesperetin) at the inflammatory area wherein the temperature is slightly above that of the normal tissue; thus, if it was at the same temperature as the normal tissue, the drug was protected inside the micelles. The micelles drug release amounts at 1,3 , $6,9,12,24$, and $36 \mathrm{~h}$ of $\mathrm{pH} 6.6$ at $39^{\circ} \mathrm{C}$ were $4.79816,5.13189$, $6.28425,7.66239,7.6419,7.93533$, and $8.59221 \mu \mathrm{g}$. The micelles drug release amounts at $1,3,6,9,12,24$, and $36 \mathrm{~h}$ of $\mathrm{pH} 7.4$ at $39^{\circ} \mathrm{C}$ were $0.42561,0.06561,0.11299,1.36382,1.306,1.29812$, and $1.53725 \mu \mathrm{g}$, as shown in Figure 9.

It can be seen from the results that when the ambient temperature was higher than the LCST, the drug (Hesperetin) was released due to the change of the micelles morphology. When the 
release time was $\sim 9 \mathrm{~h}$, the cumulative release amount reached a saturated state.

\section{Micelles in vitro Test}

The micelles in vitro test was divided into two parts: the cell viability test and the inflammatory effect. A L929 mouse fibroblast was used for the cell viability test, and a RAW264.7 mouse macrophage/monocyte was used for the inflammatory response. As shown in Figure 10, the cell viability was $\sim 90 \%$. For an intake concentration of $50 \mu \mathrm{g} / \mathrm{mL}$, the cell viability of $\mathrm{P}_{5} \mathrm{DF}_{10}, \mathrm{P}_{10} \mathrm{DF}_{10}$, and $\mathrm{P}_{20} \mathrm{DF}_{10}$ were $90,91.11$, and $88.88 \%$; in a drug intake concentration $100 \mu \mathrm{g} / \mathrm{mL}$, the cell viability of

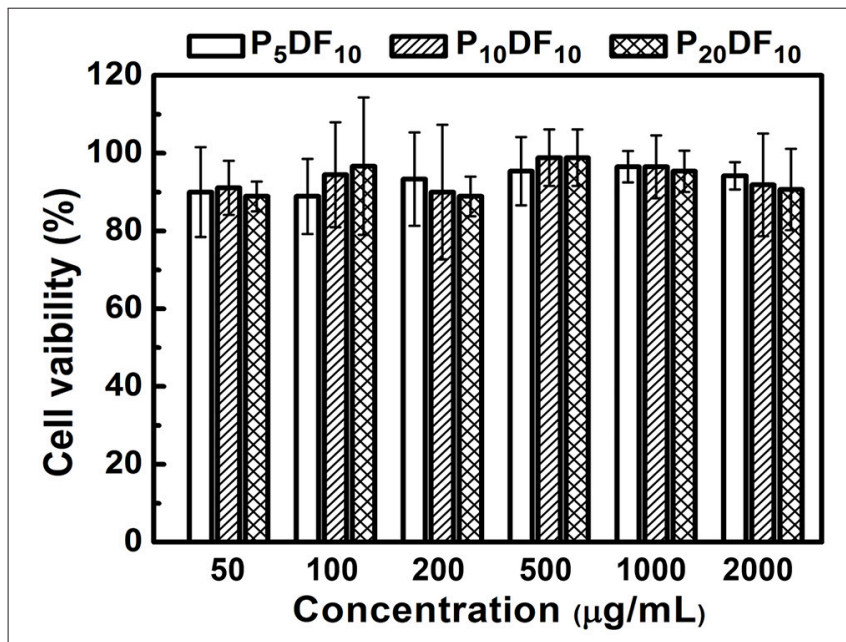

FIGURE 10 The cell viability test of $\mathrm{P}_{5} \mathrm{DF}_{10}, \mathrm{P}_{10} \mathrm{DF} \mathrm{F}_{10}$, and $\mathrm{P}_{20} \mathrm{DF} \mathrm{F}_{10}$. The cell viability was around $90 \%$ in different intake concentration of $\mathrm{P}_{5} \mathrm{DF}_{10}$, $\mathrm{P}_{10} \mathrm{DF}_{10}$, and $\mathrm{P}_{20} \mathrm{DF}_{10}$ that showed the good biocompatibility of micelles.
$\mathrm{P}_{5} \mathrm{DF}_{10}, \mathrm{P}_{10} \mathrm{DF}_{10}$, and $\mathrm{P}_{20} \mathrm{DF}_{10}$ were $88.89,94.44$, and $96.66 \%$; in a drug intake concentration $200 \mu \mathrm{g} / \mathrm{mL}$, the cell viability of $\mathrm{P}_{5} \mathrm{DF}_{10}, \mathrm{P}_{10} \mathrm{DF}_{10}$, and $\mathrm{P}_{20} \mathrm{DF}_{10}$ were $93.33,90$, and $88.88 \%$. These results showed that $\mathrm{P}_{5} \mathrm{DF}_{10}, \mathrm{P}_{10} \mathrm{DF}_{10}$, and $\mathrm{P}_{20} \mathrm{DF}_{10}$ all had good biocompatibility and low toxicity to L929 mouse fibroblasts.

In addition to their drug release function, the multi-functional drug carrier micelles are expected to reduce inflammation in cell tissues. Figure 11 showed the Hesperetin-embed $\mathrm{P}_{10} \mathrm{DF}_{10}$ micelles in cell study to confirm the anti-inflammatory property. By immunofluorescent staining of p65, we observed that p65 was exclusively distributed in the cytoplasmic and nucleus after LPS stimulation, as shown in Figure 11A. The nuclear translocation of p65 was markedly attenuated in a dose-dependent manner by Hesperetin-embed $\mathrm{P}_{10} \mathrm{DF}_{10}$ micelles treatment from 250, 500 , to $1,000 \mu \mathrm{g} / \mathrm{ml}$. These results indicated the potential role of NF- $\kappa \mathrm{B}$ in the suppression of inflammatory mediators-TNF$\alpha$ and IL- 6 production by Hesperetin-embed $\mathrm{P}_{10} \mathrm{DF}_{10}$ micelles. Figure 11B showed the Hesperetin-embed $\mathrm{P}_{10} \mathrm{DF}_{10}$ micelles and the RAW264.7 were used in the inflammatory response test. RAW264.7 cells show non-inflamed to negative control, while an inflammatory ratio $100 \%$ to positive controls. The inflammatory ratio in the Hesperetin-embed $\mathrm{P}_{10} \mathrm{DF}_{10}$ micelles concentration at levels of $1,000,500$, and $250 \mu \mathrm{g} / \mathrm{mL}$ were $36.90,56.58$, and $72.43 \%$. The results showed that the drug Hesperetin was released into the inflammatory cells and that the higher the concentration of Hesperetin-embed $\mathrm{P}_{10} \mathrm{DF}_{10}$ micelles was, the more it inhibited inflammation.

\section{DISCUSSION}

The multi-functional drug carrier micelles were synthesized by PNDU- $\mathrm{NH}_{2}$ and $\mathrm{CM}-\mathrm{Dextran} / \mathrm{Fe}_{3} \mathrm{O}_{4}$, and the functional groups were confirmed by FT-IR and ${ }^{1} \mathrm{H}-\mathrm{NMR}$. TGA and

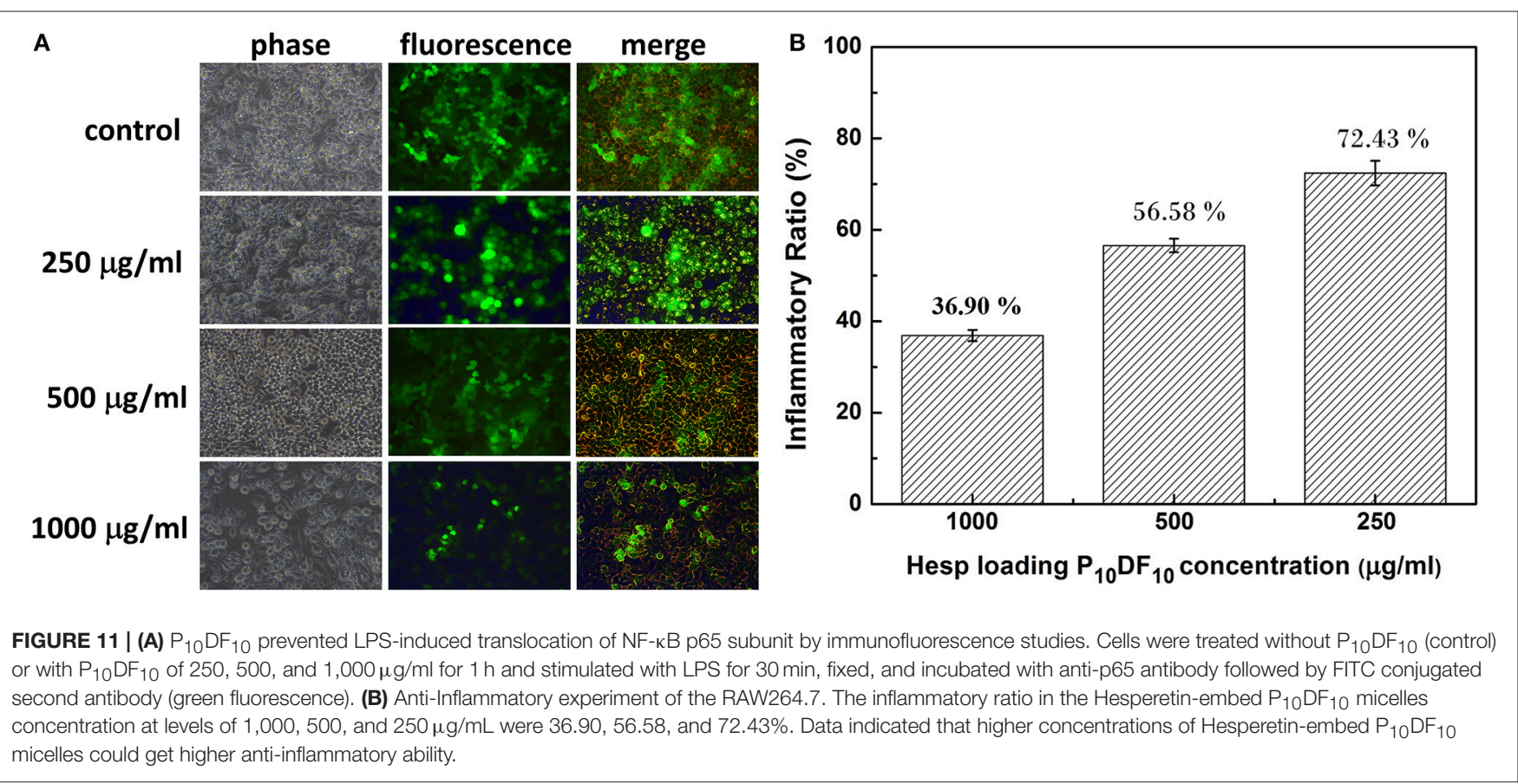


SQUID verified the CM-Dextran $/ \mathrm{Fe}_{3} \mathrm{O}_{4}$ ratio and the magnetic properties of the micelles and we observed the morphology of micelles by using TEM. This study regulated the composition of CM-Dextran $/ \mathrm{Fe}_{3} \mathrm{O}_{4}$ and PNDU-NH $\mathrm{H}_{2}$ to optimize LCST finding that it was suitable for the lesion area at a slightly higher temperature than normal tissues; it also responded to the environments of normal tissue ( $\mathrm{pH7.4)}$ and lesions ( $\mathrm{pH6.6)}$, which confirmed that the micelles had $\mathrm{pH}$ and temperature response behaviors. The drug Hesperetin was selected in this study as the drug carrier to reduce the oxidation of LDL with the aim of reducing the occurrence of atherosclerosis; in addition, it was expected to increase the therapeutic effect as well. The Hesperetin released from the micelles reached saturation after $9 \mathrm{~h}$, and the release amount of pH6.6 and pH7.4 after $36 \mathrm{~h}$ were $8.59221 \mu \mathrm{g}$ and $1.53725 \mu \mathrm{g}$, respectively. This achieved the aim of drug release in the lesion area. The in vitro test for cell viability and inflammation assessment was investigated. A L929 mouse fibroblast and $\mathrm{P}_{5} \mathrm{DF}_{10}, \mathrm{P}_{10} \mathrm{DF}_{10}$, and $\mathrm{P}_{20} \mathrm{DF}_{10}$ were used in a cell viability test. The cell viability was around $90 \%$ in concentrations of 200,100 , and $50 \mu \mathrm{g} / \mathrm{ml}$ and it possessed good biocompatibility. The RAW264.7 macrophage/monocyte was used in the inflammatory response test. At a concentration of $1,000 \mu \mathrm{g} / \mathrm{ml}$, the inflammatory ratio can be effectively reduced to $36.9 \%$, which realizes the function of the drug carrier micelles. The main challenging task is to develop a drug deliver micelles capable of responding to such a narrow range of $\mathrm{pH}$-dependent LCST in inflammation foci. The micelles synthesized in this study showed the good outcomes form the LCST results and anti-inflammation drug releasing tests in a narrow window of $\mathrm{pH}$ change of 6.6 and 7.4, which compared other micelles $\mathrm{pH}$ dependent LCST responding to different $\mathrm{pH}$ value of 5.5 and 7.4 (Yu et al., 2014) and pH value of 5 and 7.4 (Chen et al., 2013). In addition, magnetic nanoparticle grafted on PNDU micelles provided a higher magnetic property which was $6.67 \mathrm{emu} / \mathrm{g}$, than others MNPs-loaded micelles $0.06 \mathrm{emu} / \mathrm{g}$ (Yang et al., 2016), 1.71 $\mathrm{emu} / \mathrm{g}$ (Naous et al., 2017) it promoted the potential of magnetic targeting or other manipulating application.

\section{CONCLUSION}

This study successfully provided multi-functional drug carrier Hesperetin-embed micelles with good biocompatibility, while maintaining the characteristics of $\mathrm{PH}$-dependent temperature response, and magnetic properties. The drug carrier magnetic micelles were synthesized by PNDU$\mathrm{NH}_{2}$ and CM-Dextran/ $/ \mathrm{Fe}_{3} \mathrm{O}_{4}$, and the functional groups were confirmed. This study regulated the composition of CM-Dextran/ $/ \mathrm{Fe}_{3} \mathrm{O}_{4}$ and PNDU-NH $\mathrm{N}_{2}$ to optimize LCST

\section{REFERENCES}

Bok, S. H., Lee, S. H., Park, Y. B., Bae, K. H., Son, K. H., Jeong, T. S., et al. (1999). Plasma and hepatic cholesterol and hepatic activities of 3-hydroxy-3methyl-glutaryl-CoA reductase and acyl CoA: cholesterol transferase are lower in rats fed citrus peel extract or a mixture of citrus bioflavonoids. J. Nutr. 129, 1182-1185. doi: 10.1093/jn/129.6.1182 finding in $\mathrm{P}_{10} \mathrm{DF}_{10}$ that it was suitable for the lesion area at a slightly higher temperature than normal tissues. In the drug hesperetin release experiment, $\mathrm{P}_{10} \mathrm{DF}_{10}$ micelles approximately higher 5.7 times in pH6.6 than in pH7.4 showed that using these magnetic micelles, moderately hydrophobic drugs can selectively deliver to acidic inflammation foci. Its iron content was nearly about $45 \%$ and it was provided magnetic properties $(6.67 \mathrm{emu} / \mathrm{g})$, it promoted the potential of magnetic targeting. Data provided the evidence for suggesting that Hesperetin-embed $\mathrm{P}_{10} \mathrm{DF}_{10}$ micelles suppressed LPSinduced inflammatory response. Via immunofluorescence cell staining demonstrate that Hesperetin-embed $\mathrm{P}_{10} \mathrm{DF}_{10}$ micelles inhibited the activation of NF- $\kappa \mathrm{B}$ p 60 and markedly attenuated in a drug dose-dependent manner. At a concentration of $1,000 \mu \mathrm{g} / \mathrm{ml}$ in Hesperetin-embed $\mathrm{P}_{10} \mathrm{DF}_{10}$ micelles, the inflammatory ratio can be effectively reduced to $36.9 \%$, suggesting that these magnetic micelles can be a good candidate for anti-inflammatory therapy in the further clinical trial.

\section{AUTHOR CONTRIBUTIONS}

W-JW contributed substantially to the conception and selection of the drug in micelles. W-JW is the PI of the project of magnetic micelles application with hesperetin treatment from Taoyuan General Hospital, Ministry of Health and Welfare. $\mathrm{W}$-JW also assisted in carrying out in vitro tests with a magnetic micelles dosage for inflammatory study. $\mathrm{Y}-\mathrm{CH}$ is the master student from Prof. Ger's lab and has significant experience in synthesizing temperature-responsive magnetic micelles and shares first authorship. C-MS played an important role in PNDU synthesis and was of great support for the development of $\mathrm{pH}$ responsive micelles. T-RG is the research adviser of $\mathrm{Y}-\mathrm{CH}$ and C-MS, and is also a co-PI of the project from Taoyuan General Hospital, Ministry of Health and Welfare. He also wrote this manuscript.

\section{ACKNOWLEDGMENTS}

This manuscript is dedicated to the memory of Prof. Shyh-Liang Lou, who sadly passed away on 12 September 2016, whose insightful thoughts greatly impacted on this paper. This work was partly supported by the Ministry of Science and Technology, Taiwan, under Grant no. MOST 104-2112-M-033-008-MY2 and MOST 105-2221-E-033006-, a grant from Taoyuan General Hospital, Ministry of Health and Welfare, and Changhua Christian Hospital, Changhua, Taiwan. 
Das, M., Wang, C., Bedi, R., Mohapatra, S. S., and Mohapatra, S. (2014). Magnetic micelles for DNA delivery to rat brains after mild traumatic brain injury. Nanomedicine 10, 1539-1548. doi: 10.1016/j.nano.2014.01.003

Draye, J. P., Delaey, B., Van de Voorde. A., Van Den Bulcke A., De Reu. B., and Schacht, E. (1998). In vitro and in vivo biocompatibility of dextran dialdehyde cross-linked gelatin hydrogel films. Biomaterials 19, 1677-1687. doi: 10.1016/S0142-9612(98)00049-0

Fan, G. W., Zhang, Y., Jiang, X., Zhu, Y., Wang, B., Su, L., et al. (2013). Antiinflammatory activity of baicalein in LPS-stimulated RAW264.7 macrophages via estrogen receptor and NF-кB-dependent pathways. Inflammation 36,1584-1591. doi: 10.1007/s10753-013-9703-2

Francisco, V., Costa, G., Figueirinha, A., Marques, C., Pereira, P., Miguel Neves B., et al. (2013). Anti-inflammatory activity of Cymbopogon citratus leaves infusion via proteasome and nuclear factor- $\mathrm{\kappa} \mathrm{B}$ pathway inhibition: contribution of chlorogenic acid. J. Ethnopharmacol. 148, 126-134. doi: 10.1016/j.jep.2013.03.077

Gao, G. H., Lee, J. W., Nguyen, M. K., Im, G. H., Yang, J., Heo, H., et al. (2011). pH-responsive polymeric micelle based on PEG-poly ( $\beta$-amino ester)/(amido amine) as intelligent vehicle for magnetic resonance imaging in detection of cerebral ischemic area. J. Control. Release 155, 11-17. doi: 10.1016/j.jconrel.2010.09.012

Garg, A., Garg, S., Zaneveld, L. J., and Singla, A. K. (2001). Chemistry and pharmacology of the citrus bioflavonoid hesperidin. Phytother. Res. 15, 655-669. doi: 10.1002/ptr.1074

Kim, H. K., Jeong, T. S., Lee, M. K., Park, Y. B., and Choi, M. S. (2003). Lipidlowering efficacy of hesperetin metabolites in high-cholesterol fed rats. Clin. Chim. Acta 327, 129-137. doi: 10.1016/S0009-8981(02)00344-3

Kum, C. H., Cho, Y., Seo, S. H., Joung, Y. K., Ahn, D. J., and Han, D. K. (2014). A poly(lactide) stereocomplex structure with modified magnesium oxide and its effects in enhancing the mechanical properties and suppressing inflammation. Small 10, 3783-3794. doi: 10.1002/smll.201302880

Lin, H. Y., Shen, S. C., and Chen, Y. C. (2005). Anti-inflammatory effect of heme oxygenase 1: glycosylation and nitric oxide inhibition in macrophages. J. Cell. Physiol. 202, 579-590. doi: 10.1002/jcp.20160

Mohamed, E. A., Abu Hashim. I. I., Yusif, R. M., Shaaban, A. A. A., ElSheakh, A. R., Hamed, M. F., et al. (2018). Polymeric micelles for potentiated antiulcer and anticancer activities of naringin. Int. J. Nanomed. 13, 1009-1027. doi: 10.2147/IJN.S154325

Morson, B. C. (1970). Pathology of Inflammatory Diseases. Proc. R. Soc. Med. 63, 63.

Naghavi, M., John, R., Naguib, S., Siadaty, M. S., Grasu, R., Kurian, K. C., et al. (2002). pH Heterogeneity of human and rabbit atherosclerotic plaques; a new insight into detection of vulnerable plaque. Atherosclerosis 164, 27-35. doi: 10.1016/S0021-9150(02)00018-7

Naous, M., García-Gómez, D., López-Jiménez, F. J., Bouanani, F., Lunar, M. L., and Rubio, S. (2017). Multicore magnetic nanoparticles coated with oligomeric micelles: characterization and potential for the extraction of contaminants over a wide polarity range. Anal. Chem. 89, 1353-1361. doi: 10.1021/acs.analchem.6b04411

Pan, G., Guo, Q. P., Ma, Y., Yang, H. L., and Li, B. (2013). Thermo-responsive hydrogel layers imprinted with RGDS peptide: a system for harvesting cell sheets. Angew. Chem. 125, 7045-7049. doi: 10.1002/ange.201300733

Pan, G., Liu, S., Zhao, X., Zhao, J., Fan, C., and Cui, W. (2015). Fullcourse inhibition of biodegradation-induced inflammation in fibrous scaffold by loading enzyme-sensitive prodrug. Biomaterials 53, 202-210. doi: 10.1016/j.biomaterials.2015.02.078

Ross, R. (1999). Atherosclerosis-an inflammatory disease. N. Engl. J. Med. 340, 115-126. doi: 10.1056/NEJM199901143400207

Rossol, M., Heine, H., Meusch, U., Quandt, D., Klein, C., Sweet, M. J., et al. (2011). LPS-induced cytokine production in human monocytes and macrophages.
Crit. Rev. Immunol. 31, 379-446. doi: 10.1615/CritRevImmunol.v31.i5.20

Schattling, P., Jochum, F. D., and Theato, P. (2014). Multi-stimuli responsive polymers-the all-in-one talents. Polymer Chem. 5, 25-36. doi: 10.1039/C3PY00880K

Schleich, N., Po, C., Jacobs, D., Ucakar, B., Gallez, B., Danhier, F., et al. (2014). Comparison of active, passive and magnetic targeting to tumors of multifunctional paclitaxel/SPIO-loaded nanoparticles for tumor imaging and therapy. J. Control. Release 194, 82-91. doi: 10.1016/j.jconrel.2014. 07.059

Shin, E. M., Zhou, H. Y., Guo, L. Y., Kim, J. A., Lee, S. H., Merfort, I., et al. (2008). Anti-inflammatory effects of glycyrol isolated from Glycyrrhiza uralensis in LPS-stimulated RAW264.7 macrophages. Int. Immunopharmacol. 11, 1524-1532. doi: 10.1016/j.intimp.2008.06.008

Shin, Y. W., Bok, S. H., Jeong, T. S., Bae, K. H., Jeoung, N. H., Choi, M. S., et al. (1999). Hypocholesterolemic effect of naringin associated with hepatic cholesterol regulating enzyme changes in rats. Int. J. Vitam. Nutr. Res. 69, 341-347. doi: 10.1024/0300-9831.69.5.341

Soppimath, K. S., Tan, D. C. W., and Yang, Y. Y. (2005). pH-triggered thermally responsive polymer core-shell nanoparticles for drug delivery, Adv. Mater. 17, 318-323. doi: 10.1002/adma.200401057

Wei, J. S., Zeng, H. B., Liu, S. Q., Wang, X. G., Tay, E. H., and Yang, Y. Y. (2005). Temperature- and $\mathrm{pH}$-sensitive core-shell nanoparticles selfassembled from poly(n-isopropylacrylamide-co-acrylic acid-co-cholesteryl acrylate) for intracellular delivery of anticancer drugs. Front. Biosci. 10, 3058-3067. doi: 10.2741/1762

Yang, H. Y., Jang, M. S., Gao, G. H., Lee, J. H., and Lee, D. S. (2016). $\mathrm{pH}$-responsive biodegradable polymeric micelles with anchors to interface magnetic nanoparticles for MR Imaging in detection of cerebral ischemic area. Nanoscale 8, 12588-12598. doi: 10.1039/C5NR06542A

Yoon, S. J., Kim, S. H., Ha, H. J., Ko, Y. K., So, J. W., Kim, M. S., et al. (2008). Reduction of inflammatory reaction of poly(d,l-lactic-co-glycolic Acid) using demineralized bone particles. Tissue Eng. Part A 14, 539-547. doi: 10.1089/tea.2007.0129

Yu, Y., Zhang, X., and Qiu, L. (2014). The anti-tumor efficacy of curcumin when delivered by size/charge-changing multistage polymeric micelles based on amphiphilic poly( $\beta$-amino ester) derivates. Biomaterials 35, 3467-3479. doi: 10.1016/j.biomaterials.2013.12.096

Yuan, Z. M., Zhao, J. W., Zhu, W. K., Yang, Z. L., Li, B., Yang, H. L., et al. (2014). Ibuprofen-loaded electrospun fibrous scaffold doped with sodium bicarbonate for responsively inhibiting inflammation and promoting muscle wound healing in vivo. Biomater. Sci. 2, 502-511. doi: 10.1039/C3BM60198F

Zhang, L., Guo, R., Yang, M., Jiang, X., and Liu, B. (2007). Thermo and pH dual-responsive nanoparticles for anti-cancer drug delivery. Adv. Mater. 19, 2988-2992. doi: 10.1002/adma.200601817

Zu, Y., Wang, D., Zhao, X., Jiang, R., Zhang, Q., Zhao, D., et al. (2011). A novel preparation method for camptothecin (CPT) loaded folic acid conjugated dextran tumor-targeted nanoparticles. Int. J. Mol. Sci. 12, 4237-4249. doi: 10.3390/ijms12074237

Conflict of Interest Statement: The authors declare that the research was conducted in the absence of any commercial or financial relationships that could be construed as a potential conflict of interest.

Copyright (c) 2019 Wang, Huang, Su and Ger. This is an open-access article distributed under the terms of the Creative Commons Attribution License (CC BY). The use, distribution or reproduction in other forums is permitted, provided the original author(s) and the copyright owner(s) are credited and that the original publication in this journal is cited, in accordance with accepted academic practice. No use, distribution or reproduction is permitted which does not comply with these terms. 